\title{
Influence of Discovery Learning Supported by Solar System Scope Application on Students' Curiosity: The Case of Teaching Solar System
}

\author{
Atika Zahara $^{1}$, Selly Feranie $^{2}$, Nanang Winarno ${ }^{3}$ \\ \{zaharaatika@gmail.com ${ }^{1}$, feranie@upi.edu ${ }^{2}$, nanang_winarno@upi.edu ${ }^{3}$ \} \\ Department of Science Education, Universitas Pendidikan Indonesia, \\ Jl. Dr. Setiabudi 229, Bandung, 40154, Indonesia ${ }^{1,3}$, Department of Physics Education, Universitas \\ Pendidikan Indonesia, J1. Dr. Setiabudi 229, Bandung, 40154, Indonesia ${ }^{2}$
}

\begin{abstract}
Education in the Industrial Revolution 4.0 requires students to understand how they can use technology and connect knowledge with the real world. This study aimed to investigate the influence of implementing discovery learning supported by the Solar System Scope application on students' curiosity. The method used is a weak experiment. The one group pre-test post-test is used in this research as a research design. Participants were $317^{\text {th }}$ grade students at one Junior High School in Bandung, Indonesia. The result of students' curiosity after implementing the treatment enhanced with N-Gain 0.38 which categorized as medium. The treatment also enhances the students in the very good category of $54.83 \%$ with the highest improvement in science and embrace aspects. Based on these results showed that discovery learning supported by Solar System Scope application can be an alternative learning tool to enhance students' curiosity.
\end{abstract}

Keywords: Discovery earning, Solar system scope application, Students' curiosity, Solar system

\section{Introduction}

Revolution industry 4.0 in education refers to the students to understand how they can use and correlate the knowledge to the real world and knowing exactly whether, when, and where they can use the technology. This is in line with the purpose of curriculum 2013 which is chosen as an education system in Indonesia. Today's education demands the curriculum to be able to accommodate and approach students' emotional, physical, and academic. It means the teacher should develop the value and skills of students, so the students not only develop in the knowledge aspect, but they also become a creative student to face everchanging times [1]. Before the treatment done by the researcher, the researcher conducts an interview and observation with some students in the school. They were stated that physics is the most difficult subject in science. This statement also supported by Ornek, Robinson, and Haugan [2] that the most difficult subject in science is physics since the students have to comprehend the science content with different representations. The learning environment also influences students learning in science, they consider that the teacher only does a traditional teaching-learning (passive learning).

Based on the problems found in the school, another way to reach the standard or to achieve the purpose of education in this era is students are required to have high curiosity 
because the context of curiosity is important at school [3]. When students feel curious about something, they devote a lot of attention to an activity, process information deeper, and remember the information better [4]. It means students with high curiosity will have a good understanding of learning because they will find the information until they can answer it. The basis of science teaching is understanding that natural phenomena and the nature of science require inquiring and discovering, it is consists of experiments and inquiring natural phenomena by discovery learning [5]. Several studies about discovery learning were done by researchers who used it in their teaching-learning process. Using discovery learning is considered to increase students' success and inquiry learning skills more than traditional teaching methods [6]. The other researchers also found that during the exercise using discovery learning, students found themselves engaged in a fairly challenging cognitive activity, it is useful in getting students interested and curious [7].

The focus on the problem found in school about learning science, one of the topics that students will get theoretical content that has to be understood is the solar system. The hardest part of learning the solar system is not every single object or phenomenon in the solar system could be observed directly, such as the character and movement of each planet and the process of the lunar and solar eclipse. To make the teaching-learning process more efficient and accurate, it is better to apply technology such as simulation for the solar system. Virtualization on science has a way to observe natural phenomena which, perhaps because of their location, duration, and size, are impossible to directly observe [8]. By using planetarium virtual environments, students will get the experience of a phenomenon or a place that seems so difficult and impossible to observe directly in real life [9]. Solar System Scope application is one of the planetarium software to see the virtualization of the solar system to help the students identify or observe the solar system. The application can be the technical support in discovery learning for the solar system topic because discovery learning can be used as a learning model in learning the solar system and the Solar System Scope application is the facilitation to help students to observe the solar system.

There are several studies about discovery learning supported by technology which is computer-based simulation [10]. However, the differences between this research with those previous research are implementing discovery learning as a learning model using the Solar System Scope app as technical support. This research also analyzes the effect of discovery learning towards students' curiosity which has not been studied before. Through this research, it can deliver the material of the solar system in another way with easily understand, more creative, and an interesting way for the teacher. Students will also understand the concept easily and give them a new experience in learning the solar system. This research aims to investigate the effect of discovery learning supported by the Solar System Scope application on students' curiosity.

\section{Research Method}

The method which was used as a weak experimental method with one group pretestposttest design. Both method and design are involving one group that is pretested, exposed to a treatment, then post-tested. That is related to the purpose of this study which is to investigate the influence of discovery learning supported by Solar System Scope application towards students' curiosity in learning solar systems. Table 1 shows how the research design used in this study. 
Table 1. One Group Pretest-Posttest Design

\begin{tabular}{ccc}
\hline $\mathrm{O}$ & $\mathrm{X}$ & $\mathrm{O}$ \\
\hline Pretest & Treatment & Posttest
\end{tabular}

The population in this research is all students in one of the classes in $7^{\text {th }}$ grade at one of Junior High School in Bandung. The sampling technique used in this research was convenience sampling, the researcher selects participants because they are available to be studied. There are 31 students in one class at this school with 13 male students and 18 female students with an age average of 12-13 years old. The treatment refers to learning activity by implementing discovery learning supported by the Solar System Scope application. This application facilitates students with some features to observe the objects in the solar system such as the planet explore, star explore, near stars, and messier objects by selecting the object or typing the name. The special one is the user can just place their phone directly to the sky and see what solar system object in the sky at that time. The picture of the Solar System Scope application can be seen in Figure 1.

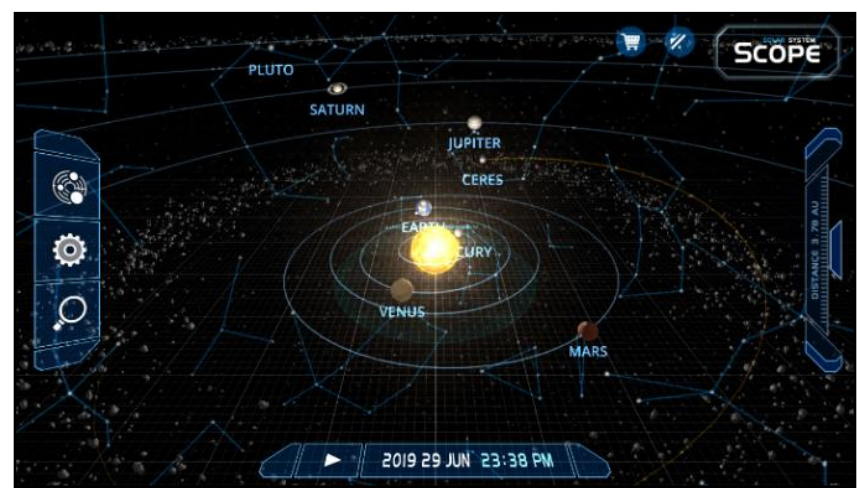

Fig. 1. Solar System Scope Application

This research through some steps, the first researcher analyzes the curriculum 2013, discovery learning and Solar System Scope application. After conduct, some analysis, the researcher arranges the instruments which are consist of an observation sheet and questionnaire of students' curiosity, then validate the instrument and revise it. In the implementation stage, the researcher conducts the treatment by giving a pretest in the beginning, implementing the treatment, and posttest. The treatment was done by implementing discovery learning as a learning model using a syntax based on Joyce, Weil, and Showers [11] with technology supported by the Solar System Scope application. Data is obtained from pretest and postest by giving students a questionnaire adopted from SCILE by Weible and Zimmerman [12] consist of 12 questions with 3 aspects which are science, stretch, and embrace. The questionnaire was measured with a five-Likert scale which is always, often, sometimes, not often, and never. Each scale has a different score from another, the score for always is 5 , often is 4 , sometimes is 3 , not often is 2 , and never is 1 . Then it comes to the completion stage which is the process the data, analyze it, and conclude the result. 


\section{Results and Discussion}

\subsection{The Effect of Discovery Learning Supported by Solar System Scope Application on Students' Curiosity}

The questionnaire was given to the students as a tool to see the students' curiosity before the teaching-learning process and after the teaching-learning process. The questionnaire was adapted from Science Curiosity in Learning Environment (SCILE) by Weible and Zimmerman [12] and has been given to the students in the class. To obtain the result of the questionnaire, it was analyzed by Microsoft Excel 2013 and also analyzed by using the gain normalized test based on the Hake's rule of normalization. The average N-gain score of students' curiosity in pretest and posttest showed in Table 2.

Table 2. Students' Curiosity Score for Pretest and Posttest

\begin{tabular}{ccccc}
\hline & Average & Gain & N-gain & Category \\
\hline Pretest & 67 & 12 & 0.38 & Medium \\
Posttest & 79 & & & \\
\hline
\end{tabular}

The average score of students' curiosity before learning activity using discovery learning supported by Solar System Scope application is 67 and that the average score of students' curiosity after teaching-learning activity using discovery learning supported by Solar System Scope application is 79 . The data conclude that there is an enhancement on students' curiosity with gain 12 and $\mathrm{N}$-gain 0.38 after the treatment done in the class. Based on Hake's rules of normalization, this score $\mathrm{N}$-gain is categorized as medium. To see the detail of the students' category in the level of curiosity, then the data is also analyzed in each student for pretest and posttest using interpretation criteria score of curiosity in percentage. The result of students' curiosity in detail is presented in Figure 2.

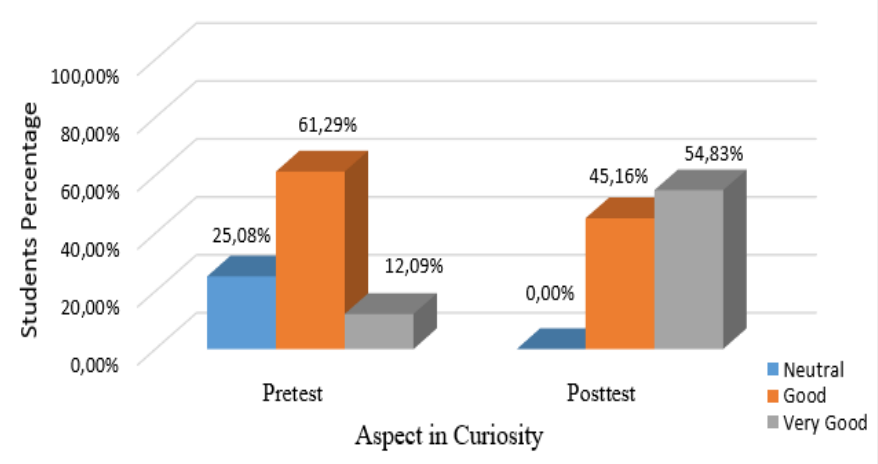

Fig. 2. Total Number of Students for Each Category in Curiosity Before and After Learning

From Figure 2, the total number of students in a neutral category is decreasing after learning activity which from $25.08 \%$ to $0 \%$ and it also happened in a good category from $61.29 \%$ to $44.16 \%$. While after learning activity for a very good category is increase well which is become 17 students $(54.83 \%)$ from 4 students $(21.09 \%)$. It means there is an 
enhancement for students' curiosity after implementing discovery learning and using Solar System Scope application for learning activity since the number of students for a very good category in curiosity is increasing. Mukherjee (2015) found that using discovery learning is useful in getting students interested and curious because, during the exercise, students found themselves engaged in a fairly challenging cognitive activity. This statement could support about the decreasing number of students in the very good category for curiosity after implementation of discovery learning.

The feeling of curios is stimulating people when they feel they are a shortcoming of meaningful information so they need to find the answer to a complex question, a meaningful fact, or a problem solution [13]. In this case, students have the opportunity to freely explore anything they want to, this is also in line with researcher conducted by Veermans, De Jong, and Van Joolingne [14] learners (learning using discovery learning) can generate data and are expected to extract and construct knowledge from these data. Using discovery learning students are need to exploring, seeking new information or experience from answer the problem or hypothesis, this statement supported by the research by Saab, Van Joolingen and van Hout-Wolters [15] they said learning using discovery learning often formulated the hypotheses will learn better.

During learning activity, students learn through some steps (syntax) based on discovery learning as a learning model, there are stimulation, problem statement, data collection, data processing, verification, and generalization. Stimulation is the first step during a learning activity, in this step students are stimulated by some questions or problems. In these steps, students will feel interested and curious to find the answer and it will motivate the students to start to learn. When students start to feel motivated and curios the next step is the problem statement. Students are asked to identify the questions, problems, or making a hypothesis. The problem is related to a phenomenon in daily life so they will feel interested.

The next step is data collection, this step asked students to answer the question or problem. In this step, the role of the Solar System Scope application as planetarium software is important. Students freely explore the application to obtain information and data. The use of the Solar System Scope application could enhance students' curiosity since they are never using any application to learn the solar system before. After collecting the data, next is data processing where students process all the information by reading and observing in the previous step or if necessary for some questions students have to calculate first then interpreted it.

The next step is verification, based on the result of the previous step which is processing the data, the questions, problems, or hypothesis that has been formulated earlier is checked. The last is a generalization since in this research students are asked to make a group so each group is asked to come in front of the class and share what information, conclusion, and concept that they have already obtained. This steps will answer their curiosity about the problem or question that they state in the first session

Besides discovery learning, the role of Solar System Scope application to support learning activity using discovery learning also important. Using planetarium software to teach solar systems makes it possible using a realistic simulation without limitations on time and location, and also it is easy and cheap to use for students [16]. One as interesting examples of Virtual Learning Environments, planetarium software, offers many possibilities for learning the solar system in a new way and beneficial ways, as the software provides students the structure, details, and complexity of the solar system through 3D visualization [17,18]. Using planetarium virtual environments, students will get experience about the phenomenon or a place that seems so difficult and impossible to observe directly in real life [9]. This could 
support the result of this research, when they feel curious about something, it will motivate them to learn more about the topic.

Solar System Scope application provides some features to students as a learner use the application. Some features that will enhance students' curiosity is explored planet system and the night sky. Planet system features are where students can explore any object and the movement of the planet and stars in the solar system with detail. The other feature is night sky where students can see the sky only by using their phone placed directly to the sky and see what objects are in the sky. Solar System Scope application provides great virtualization and animation with the true scale in the solar system, for example, the structure of the planet, the composition, the movement, and their distances. Another feature that should get appreciation is this application also supported by music so during exploring the solar system is will be different from traditional learning, it will make students motivated and curious to learn more about the solar system.

\subsection{The Effect of Discovery Learning Supported by Solar System Scope Application on Students Curiosity in Each Aspect}

The data of students' curiosity in this research also analyzed based on 3 aspects which are science, embrace and stretch. To know the effect of the treatment on students' curiosity in each aspect, the test of gain normalization was done by finding the average of pretest and posttest questionnaire score and after that calculating the gain normalization. Figure 3 shows the N-gain score of students' curiosity in each aspect.

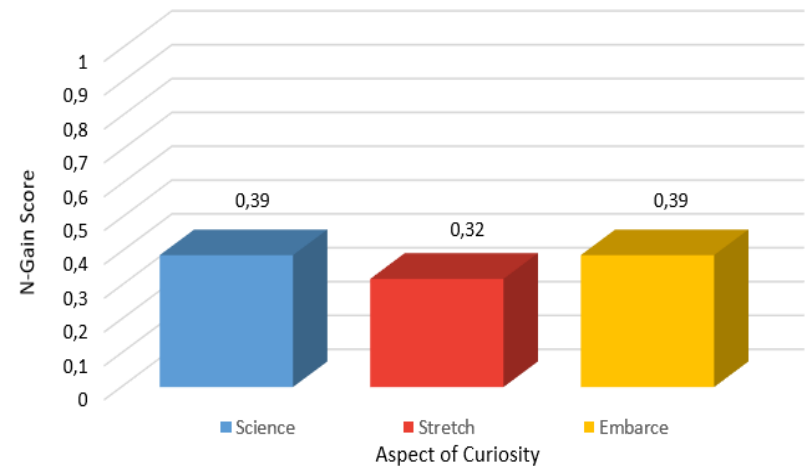

Fig. 3. N-gain Score of Students' Curiosity in Each Aspect

Figure 3 shows $\mathrm{N}$-gain score for students' curiosity in, for science aspect is 3.9 categorized as medium according to Hake's rule, N-gain score for stretch aspect is 3.2 categorized as a medium, while embrace aspect gains the same score with science aspect which is 3.9 categorized as medium. Based on Science Curiosity in Learning Environment (SCILE) by Weible and Zimmerman [11] that is used as a questionnaire to measure students' curiosity in this research, science aspect is focusing on specific behaviors, skills, and actions that are directed specifically at assessing students' curiosity in science [19].

The N-gain score of the science aspect is higher than the stretch aspect it is because students have the skill to do the experiment or create their opinion and concept based on the question or problem that given in the first session of learning activity using discovery learning 
(stimulation and problem statement steps). Students are experimenting or create their opinion by using the Solar System Scope application to gain the information, this activity is included in data collection and data processing steps. Creating or stating their opinion and concept from the data analysis (verification and generalization steps) is also included as skill in the science aspect. Using discovery learning supported by Solar System Scope application could improve students' curiosity in learning the solar system.

In this research, the stretch aspect means students' can explore or seek new information and experiences. The $\mathrm{N}$-gain score of the stretch aspect is the lowest than the science and embrace aspect. From the questionnaire statement, students need to explore or seeking new experiences by using the Solar System Scope application to gain the information based on problems or questions given to the students in stimulation and problem statement steps. Difficulties found when they need to explore and seeking the information by using the Solar System Scope application because the language is in English, so they need to translate it first into Bahasa to get the point and work the app. In general, during the data collecting and data processing students are capable to do the activity, this also happened during the verification and generalization steps. This means using discovery learning supported by the Solar System Scope application could improve students' curiosity in learning the solar system. Same with stretch aspect, embrace in this term is can be aggregated to measure students' curiosity.

According to Science Curiosity in Learning Environment (SCILE), this aspect is in line with the stretch aspect, because in embrace aspect students need the acceptance of the novel, uncertain, and unpredictable nature of everyday life. The N-gain score of embrace aspect is the same with the science aspect, it could happen because students are given the question or problem based on the phenomenon or unpredictable nature of everyday life (stimulation and problem statement). They could analyze and gain the information using the Solar System Scope application based on the phenomenon in everyday life, such as rotation and revolution of the Earth (data collecting and data processing steps). When it comes to verification and generalization, students need to have the acceptance of the novel, uncertain, and unpredictable nature of everyday life based on the information that they already obtain. Knowing that there is an enhancement in students' curiosity after analyzing the data based on a questionnaire and analyzing three aspects which are science, stretch and embrace, it can conclude that using discovery learning supported by Solar System Scope application can enhance students' curiosity in learning the solar system.

\section{Conclusions}

From the scoring results of curiosity questionnaire, the implementation of discovery learning as a learning model with technology support from Solar System Scope application could improve the students' curiosity, it can be proved by the results of N-Gain is 0,38 which means categorized as medium. The improvement of students' curiosity also supported by the decreasing of students in a category very good which from 4 students learning activity become 17 students after learning activity. It can conclude that learning the solar system using discovery learning supported by the Solar System Scope application could enhance students' curiosity. From the analysis result of the research, there is some suggestion for this research. First, the application as the technical support also should be available in Bahas, since not all of the students are fluent in English. The other suggestion is during learning activity in this research should considering the time since using discovery learning takes time in the 
implementation. However, in general, the result showed that discovery learning supported by the Solar System Scope application can be an alternative learning tool to enhance students' curiosity.

\section{References}

[1] Kementrian Pendidikan dan Kebudayaan. Materi Pelatihan Guru Implementasi Kurikulum 2013. Jakarta: Badan Pengembangan Sumber Daya Manusia Pendidikan dan Kebudayaan dan Penjaminan Mutu Pendidikan (2014)

[2] Ornek, F., Robinson, W. R., \& Haugan, M. R.: What Makes Physics Difficult?. Science Education International, 18(3), 165-172 (2007)

[3] Aschieri, F., \& Durosini, I.: Development of the self-curiosity attitude-interest scale. Testing, Psychometrics, Methodology in Applied Psychology, 22(3), 326-346. (2015)

[4] Kashdan, T. B., Gallagher, M. W., Silvia, P. J., Winterstein, B. P., Breen, W. E., Terhar, D., \& Steger, M. F.: The curiosity and exploration inventory-II: Development, factor structure, and psychometrics. Journal of research in personality, 43(6), 987-998. (2009)

[5] Bruner, J. S.: The act of discovery. Harvard Educational Review, 31, 21-32. (1961)

[6] Balım, A. G.: The Effects of Discovery Learning on Students' Success and Inquiry Learning Skills. Eurasian Journal of Educational Research (EJER), (35). (2009)

[7] Mukherjee, A.: Effective use of discovery learning to improve understanding of factors that affect quality. Journal of Education for Business, 90(8), 413-419. (2015)

[8] Furness, T. A., Winn, W., \& Yu, R.: Global change, VR and learning, A report for the NSF of workshops, The impact of three dimensional immersive VE on modern pedagogy. Seattle (WA): NSF. (1997)

[9] Dede, C.: Emerging influences of information technology on school curriculum. Journal of Curriculum Studies, 32(2), 281-303. (2000)

[10] De Jong, T., \& Van Joolingen, W. R.: Scientific discovery learning with computer simulations of conceptual domains. Review of educational research, 68(2), 179-201. (1998)

[11] Joyce, B., Weil, M., \& Showers, B.: Models of Teaching (4th ed.). Needham Height Massachusetts: Ally and Bacon. (1992)

[12] Weible, J. L., \& Zimmerman, H. T.: Science curiosity in learning environments: developing an attitudinal scale for research in schools, homes, museums, and the community. International Journal of Science Education, 38(8), 1235-1255. (2016)

[13] Litman, J. A., \& Silvia, P. J.: The latent structure of trait curiosity: Evidence for interest and deprivation curiosity dimensions. Journal of Personality Assessment, 86(3), 318-328. (2006)

[14] Veermans, K., de Jong, T., \& van Joolingen, W. R.: Promoting self-directed learning in simulation-based discovery learning environments through intelligent support. Interactive Learning Environments, 8(3), 229-255. (2000)

[15] Saab, N., Van Joolingen, W. R., \& van Hout-Wolters, B. H.: Supporting communication in a collaborative discovery learning environment: The effect of instruction. Instructional Science, 35(1), 73-98. (2007)

[16] Persson, J. R., \& Eriksson, U.: Planetarium software in the classroom. Physics Education, 51(2), 025004. (2016)

[17] Gilbert, J. K.: Visualization: An emergent field of practice and inquiry in science education. In Visualization: Theory and practice in science education (pp. 3-24). Springer, Dordrecht. (2008) [18] Mikropoulos, T. A., \& Natsis, A.: Educational virtual environments: A ten-year review of empirical research (1999-2009). Computers \& Education, 56(3), 769-780. (2011)

[19] Spektor-Levy, O., Baruch, Y. K., \& Mevarech, Z.: Science and Scientific Curiosity in Preschool-The teacher's point of view. International Journal of Science Education, 35(13), 2226-2253. (2013) 